\title{
Mast cells and pathological process in lungs of rats and mice
}

\author{
NOMEDA JUODZIUKYNIENE, ALBINA ANIULIENE, JURATE SIUGZDAITE, \\ JUDITA ZYMANTIENE*, VIDA JUOZAITIENE**, KRISTINA LASIENE**, \\ GABIJA SOKOLOVAITE****
}

\author{
Department of Veterinary Pathobiology, *Department of Anatomy and Physiology, \\ **Department of Animal Breeding, Animal Husbandry Faculty, Veterinary Academy, \\ ${ }^{* * *}$ Department of Histology and Embryology, Faculty of Medicine, Lithuanian University of Health Sciences, \\ Mickeviciaus str. 9, LT-44307, Kaunas, Lithuania \\ ****Veterinary Clinic „Toto“, I. Simulionio str. 5, Vilnius, Lithuania
}

Juodziukyniene N., Aniuliene A., Siugzdaite J., Zymantiene J., Juozaitiene V., Lasiene K., Sokolovaite G. Mast cells and pathological process in lungs of rats and mice

\section{Summary}

The aim of this study was to evaluate the number of mast cells in healthy and affected lungs of mice and rats and determine histopathological differences of the inflammatory process in the lungs of rats and mice.

The lungs of healthy and affected laboratory mice $(n=80)$ and rats $(n=80)$ were used for the studies. The histpathological examination of HE slides was performed. The number of mast cells in healthy and affected lungs of mice and rats was calcaluted in Giemsa stained slides.

The number of connective tissue mast cells in healthy animals and in areas of lymphoid hyperplasia and bronchiectasis was significantly higher in rats than in mice. Interstitial pneumonia with bronchiolitis and bronchiectasis and atelectasis was more expressed in rats $(P=0.006-0.025)$ than in mice. Lymphoid tissue hyperplasia in the lungs of mice was found much more intense than in rats $(P=0.011)$. In affected laboratory mice and rats Mycoplasma pulmonis was identified.

Interstitial pneumonia with bronchiolitis and bronchiectasis and atelectasis were more pronounced in rats. In our opinion, because healthy rats have more mast cells in the connective lung tissue and developed more severe pneumonia, they had a higher response of mast cells to the inflammatory process compared to mice. There was a more intense lymphocytic response in the lungs of mice.

Keywords: rodents, lungs, inflammation, mast cells

The laboratory mice and rats are an inevitable part of today's biomedical research and veterinary medicine. Mice and rats are extensively used in physiological research $(9,32,33)$. Almost $80 \%$ of the experimental animals in USA and European Union countries are rodents that include mice and rats. Rats and mice are employed in about $85 \%$ of the articles in Medline and $70.5 \%$ of the articles in Lilacs $(9,11)$. Usually they are kept in special conditions that meet the requirements. Despite of this, outbreaks of some infection agents can occur and cause pathological proccess without clinical signs.

Diseases of the respiratory tract, especially chronic respiratory disseases (CRD), are among the most common health problems reported in mice and rats (1, $11,15)$. The most important causative agent in rats is Mycoplasma pulmonis $(1,11)$. Although Mycoplasma pulmonis alone can be the only agent causing respiratory disease in rats and mice, most CRD is caused by a combination of mycoplasma and other agents as Streptococcus pneumoniae, Corynebacterium kutscheri, Pseudomonas aeruginosa, Pasteurella pneumotropica, cilia-associated respiratory bacillus, Bordetella bronchiseptica, Pneumocystis spp., "gray lung agent" (an unidentified mycoplasma), Sendai virus, sialodacryoadenitis virus $(1,13,29,42)$. In addition to the infectious agent, lung lesions and disease outcome are also determined by host and environmental factors $(25,45)$.

Many immune system cells are involved in the inflammatory process: neutrophils, macrophages, lymphocytes, plasmocytes, mast cells. Mast cells are a part of the immune system, originated from myeloid stem cells. They have the ability to quickly release a number 
of mediators during degranulation. Except for allergic reactions mast cells are involved in angiogenesis and immune tolerance, the cerebro-vascular barrier and in inflammation - the protection against many pathogenic factors using different mechanisms for recognition (16, $23,24,27,31,44)$. Mast cells are present in lungs of humans, rats, mice and other mammals and play an important role in the lungs in both health and disease. Fixed mast cells are found in lung epithelium and free mastocytes are in the bronchial lumen $(18,19,21$, $28,29)$ and in in the lamina propria of the bronchi as well as the supporting tissue of the bronchioles (41, 45). The protease content of mucosal mast cells is characterized by the chymases, which are bound to chondroitin sulfate chains of serglycin proteoglycans, whereas connective tisssue mast cells are found in the intestinal submucosa, peritoneum, and skin and contain the chymases, tryptases and carboxypeptidase bound to heparin chains of serglycin proteoglycans (2, $4,8,14,19,41)$. Mucosal and connective tisssue mast cells also differ in their ability to secret histamine and lipid mediators. Upon activation, mucosal mast cells release small amounts of histamine and large quantities of cysteinyl leukotrienes, whereas connective tisssue mast cells release higher levels of histamine and prostaglandin D $(19,35)$. The autonomic receptors of beta-adrenergic type and the biochemicals by which various neurotransmitters, hormones and pharmacological agents modulate the release of mast cell mediators $(4,16,17,19)$. MCs have an array of receptors to identify and react to invading bacterial pathogens. MCs also have receptors to detect bacterial-activated immune components, such as complement receptors and the receptor for the $\mathrm{Fc}$ portion of antibody $(\mathrm{FcR})$. These cells have a potent arsenal to combat bacterial infections ranging from antimicrobial peptides and proteases, for direct killing of pathogens or inhibiting growth, to secretion of chemokines and cytokines for recruitment and activation of other immune cells to facilitate control of infection (38). New investigations are performed in the last years to search a connection between lung mast cells as a culprit and respiratory disseases $(8,21,39)$.

The aim of this study was to evaluate the number of mast cells in healty and affected lungs of mice and rats and determine histopathological differences of inflammatory processes in the lungs of rats and mice.

\section{Material and methods}

Animals. We have evaluated 160 lung specimens of rodents: 80 Wistar rats and $80 \mathrm{Balb} / \mathrm{c}$ mice, collected during the years 2015-2018 from experimental enterprise of LUHS.

Healthy $(\mathrm{n}=21)$ and affected laboratory mice $(\mathrm{n}=59)$ and healthy $(\mathrm{n}=16)$ and affected $(\mathrm{n}=64)$ rats, respectively, were used for the studies due to the mild signs of the disease, and collection of rodent lungs was as additional pathological material. The rodents were kept according to welfare protocols in an experimental enterprise and the keeping conditions of animals were performed in compliance with the rules of the national Animal Ethics Committee.

Wistar strain rats and BALB/c mice were kept in 2 premises under the same normal conditions: light-dark cycle of 12 : 12 hours, temperature maintained at $22 \pm 2{ }^{\circ} \mathrm{C}$ and relative humidity was $55 \pm 5 \%$. Rats and mice were given $a d$ libitum access to high-quality feed of the same batch and water throughout the whole study. The commercial standard diet (PA-11700000-171) for rodents contained crude protein $19.91 \%$, fat $12.05 \%$, crude fiber $2.79 \%$ and $7.72 \%$ cellulose in $1 \mathrm{~kg}$ of feed. The rats and mice were housed in standard polycarbonate cages (Techniplast, Italy), the minimum enclosure size was $800 \mathrm{~cm}^{2}$, the floor area per animal $350 \mathrm{~cm}^{2}$ and a minimum of $18 \mathrm{~cm}$ height. Rats and mice were euthanized in $\mathrm{CO}_{2}$ cages $(19.05 \times 12.71 \times 29.21 \mathrm{~cm})$. The $\mathrm{CO}_{2}$ flow rate was $1.5 \mathrm{l} / \mathrm{min}$ and the final concentration of $\mathrm{CO}_{2}$ was $20 \%$.

In culled animals fur changes occurred: rats and mice coats became greasy. Only a few animal were a little depressed and anorexic for 1-2 weeks. 3 rats died in the course of the experiment. The age of animals ranged from 6 month to 2 years. Rapid unconsciousness was achieved with minimal distress to the animals.

Microbiological examination. The specimens collected from lung lesions were placed in grinding medium are macerated in a Stomacher Lab blender 80 (Fisher Scientific, UK). A portion of the tissue suspension was inoculated onto selective bacteriological culture medium. Microbiological examination of the samples from lungs was carried out using Friis selective media. The swabs were placed in the Friis NHS-20 broth by carrying out dilutions from $10^{-1}$ to $10^{-4}$ and cultivated in aerobic conditions for 3-4 days. After the color of broth culture changed indicating mycoplasma growth, broth was inoculated on to Friis NHS-20 agar plates. Solid media were incubated in microaerophillic conditions for 3-5 days. Pure cultures of M. pulmonis were purified three times by conventional filtration cloning techniques with a 450-nm pore size membrane filter. For the identification of $M$. pulmonis isolates were tested for biochemical properties: glucose fermentation, arginine hydrolysis, phosphatase activity, tetrazolium reduction.

Pathological morphological examination. Gross examination. After the death or killing of animals, gross lesions (discoloration, changes of texture, etc.) of the lungs and other organs were studied. Lungs of each rodent were taken for histopathological examination, the material was fixed in $10 \%$ neutral buffered formalin solution at room temperature for 1 week. Paraffin blocks were made using "Shandon Pathcentre" and "TES 99 Medite Medizintechnik" equipment. Serial $4-\mu \mathrm{m}$ sections from each sample were prepared with a "Sakura Accu-Cut SRM" microtome and served for routine $H \& E$ staining and staining with Giemsa stains for mast cells.

Histopathological examination. Histological slides were evaluated, and image analysis was performed using the Olympus microscope supplied with a digital Olympus DP72 image camera with CellSensDimension software. The number of mast cell in $\mathrm{mm}^{2}$ was calculated. The presence of different pathological process was established. Lung hyperemia was not considered as a pathological entity because animals were euthanized in $\mathrm{CO}_{2}$ cages. 
Assessment of mast cells number. Mast cell number in the Giemsa stained lung tissue of both healty $(\mathrm{n}=10)$ and diseased rats $(\mathrm{n}=10)$ and mice lung were evaluated (total $\mathrm{n}=40$ ). The average of connective tissue mast cells was calculated in each section, in 10 adjacent microscopic fields (MF) ( $\times 200$ magnification) of alveolar and bronchiolar tissue, but excluding major bronchi, pleura and mucosa. The average of connective tissue mast cells was calculated by two independent researchers. The Olympus microscope supplied with a digital Olympus DP72 image camera with CellSensDimension software was used.

Statistical analysis. In the present study, statistical analysis of the results was carried out using the IBM SPSS Statistics (version 20.0, IBM, Munich, Germany). The data of descriptive statistics are presented as mean \pm standard error $(\mathrm{M} \pm \mathrm{SEM})$. Differences of means between groups were determined using Student's paired $t$ test. The relationship between the categorical variables (incidences of different pathological process in mice and rats) were evaluated using $\chi^{2}$ test. The results were reliable under P level $<0.05$.

\section{Results and discussion}

The lungs of only 21 mice and 16 rats were without morphological changes (Fig. 1). Microscopical examination showed only mild hyperemia caused by euthanasia with $\mathrm{CO}_{2}$.

In 59 specimens of mice and 64 of rats lungs the inflammatory process was found. The lungs were grey-brown-white in color, affected focally or diffusely, of hard or semi-hard texture, with the sack-like dilatations of bronchi, bronchioli and surrounding lung tissue and purulent, catarrhal-purulent exudate inside. Hyperemia was more intense. Several compartments were involved in the inflammatory process including the airways (bronchi and bronchioles), the terminal bronchiole/alveolar duct region (acinar region), the alveoli or alveolar septa (interstitium), perivascular areas, and the pleura.

In microbiologial examination of lung and trachea specimens from rats and mice Mycoplasma pulmonis was detected. Mycoplasma titre was $>10^{5} \mathrm{CFU} / \mathrm{mL}$. Over 50 colonies grew on selective nutritional media.

We have found complex pathology in both mice and rats lungs.

According to the histopathological criteria, bronchointerstitial pneumonia was diagnosed in both in rats and mice: $64(80 \%)$ and $59(73.8 \%)$ animals, respectively $(\mathrm{P}=0.348)$ (Fig. 2). We have observed a prevalence of severe bronchointersticial pneumonia with severe bronchiectasis and bronchiolitis in rats, and the bronchi, bronchioli, alveoli, alveolar ducts, interstitium, perivascular area and pleura were involved. In cases of bronchointerstitial pneumonia mucopurulent exudate in bronchioles and small bronchi lumen was found. In part of the animals (in most cases in rats), exudate was composed from weakly stained mucus and neutrophils, macrophages, foamy macrophages and desquamated mucosal epithelial cells. In mice the same structures were involved and the lymphoid tissue hyperplasia was the main pathological process. In mice lungs pneumonia show more pure purulent inflammatory exudate with very aboundant neutrophils, eosinophils, foamy macrophages and desquamated epithelial cells. In alveoli, various degree of type II alveolocytes proliferation and increased number of alveolar macrophages were observed. Intraalveolar septa were found thickened, edematous, infiltrated with lymphocytes, plasmocytes and macrophages. Evidence of edema and/or hyperemia was observed. According some investigations, in rats Mycoplasma pulmonis causes mucosal epithelium hyperplasia, squamous metaplasia, inflammatory cell infiltration, hyperplasia of bronchial-associated lymphoid tissue, accumulation of lymphocytes and plasma cells around airways,

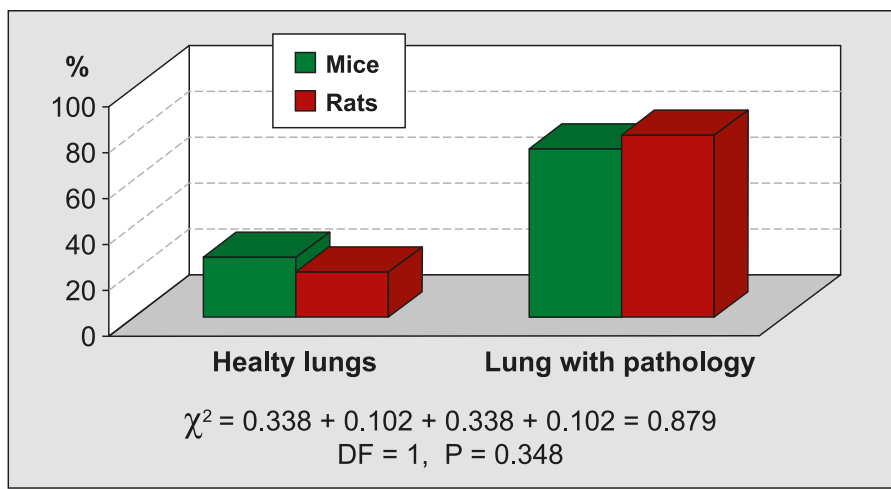

Fig. 1. Healthy and affected lungs in mice and rats (percentage)

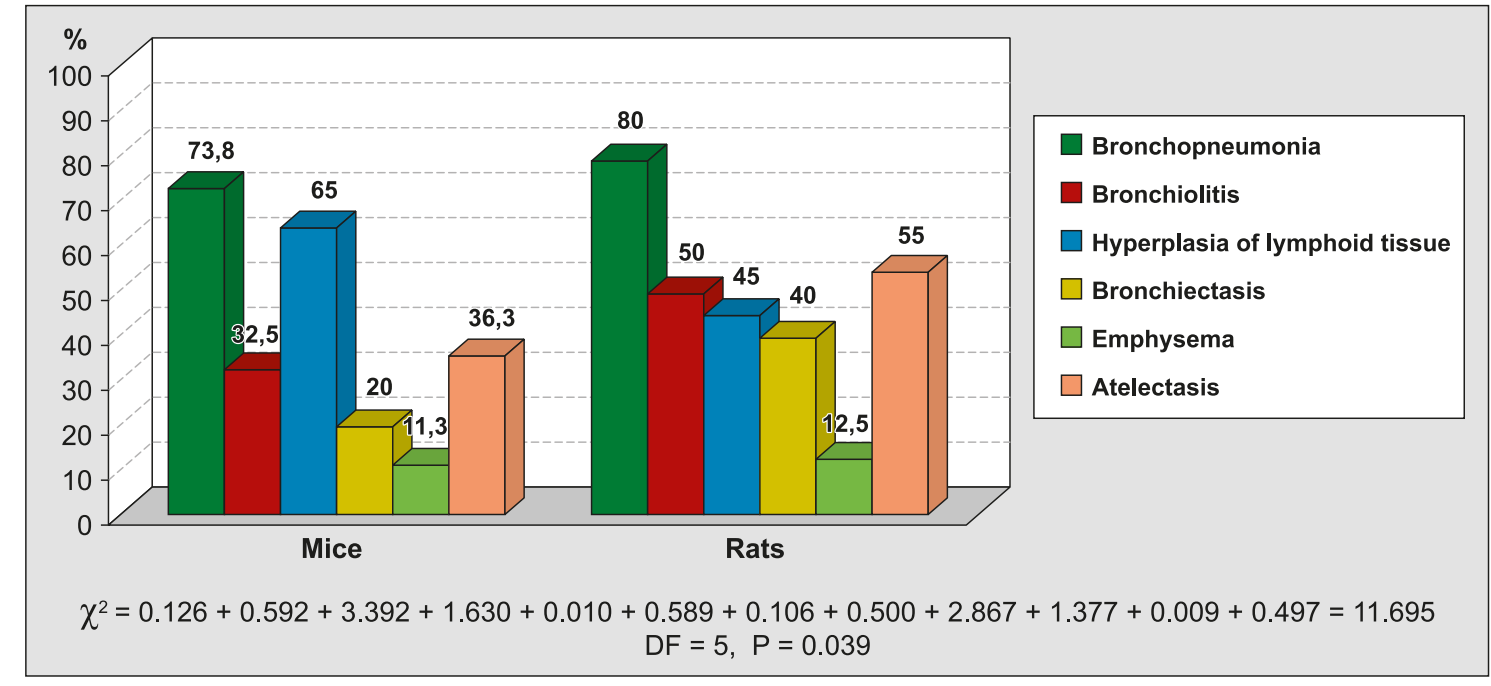

Fig. 2. Histomorphology of the inflammatory process in lungs of mice and rat (percents) 
suppurative exudate within airway lumina and alveoli, hyperplasia of alveolar type II pneumocytes $(1,5,15)$.

Lymphoid tissue hyperplasia in the lungs was found to be much more intense $(P=0.011)$ in mice (52 animals) lungs than in rats (36 animals) (Fig. 2). The peribronchial and peribronchiolar lymphoid tissue was significantly enlarged, with nodular structure, but many germinative centers were visible in the nearby lung stroma. Lymphoid tissue hyperplasia has been less pronounced in rat lungs. Lymphoid tissue was more diffuse (Fig. 8-9). Bronchial-associated lymphoid tissue hyperplasia may be partly related to the mitogenicity of M. pulmonis for rats lymphocytes. Mycoplasma pulmonis is able to evade the host immune response, leading to a persistent and chronic infection $(1,5,28)$.

Manifestation of bronchiolitis and bronchiectasis was statistically reliable $(\mathrm{P}=0.006-0.025)$, more intense in rats (32 and 40 cases) and more severe than in mice (16 and 26 cases) (Fig. 2). Bronchiolitis in mice was characterized by abundant accumulation of neutrophils, foamy macrophages in the lumen of bronchioles thogether with mucosal hyperplastic foldings in lumen but without significant narrowing of the lumen. In contrast, bronciolitis in rats was more severe: there were distinct bronchiolar lumen narrowings due prominent mucosa and submucosa connective tissue projections, abundant infiltrations with lymphocytes, plasmocytes and macrophages. Infectious agents stimulate epithelial cells and resident macrophages to secrete cytokines, thus inducing an inflammatory response and cause tissue damage, resulting in secondary inflammation $(1,5$, $15,40)$. Sendai virus infection causes proliferation and regeneration, dysplasia of upper and lower airways and alveolar septa epithelium, squamous metaplasia, polypoid masses in bronchiolar lumina can occur. Sometimes the infection outcome is full recovery. Scars, fibrosis, cholesterol clefts, dilated airways, peribronchial, peribronchiolar and perivascular mononuclear cell cuffs and aggregates can by observed $(1,5)$. We could not confirm presence of this virus.

Many immune system cells are involved in the inflammatory process: neutrophils, macrophages, lymphocytes, plasmocytes, mast cells. In case of pneumonia, the hyperemia in lungs and migration of blood monocytes, neutrophils and eosinophils to inflammatory foci occurs. Cytokines, chemokines, inflammatory mediators produced by phagocytes attract more inflammatory cells from blood as well as from tissues (mast cells) $(4,6,10,44)$. Involvement of many inflammatory cells, their interaction, releasing of some proteolytic enzymes (collagenase, elastase), harmfull effect of pathogens causes a complicated mechanism that damage lung tissue $(7,12,30)$. Bronchiectasis was much more pronounced in rats than in mice. Grossly, these lesions would be characterized by the presence of pus in distinct dilatated sack-like bronchi and bronchioli, protruding to pleural surface (Fig. 3). The lumen of bronchioli and bronchi was distinctly

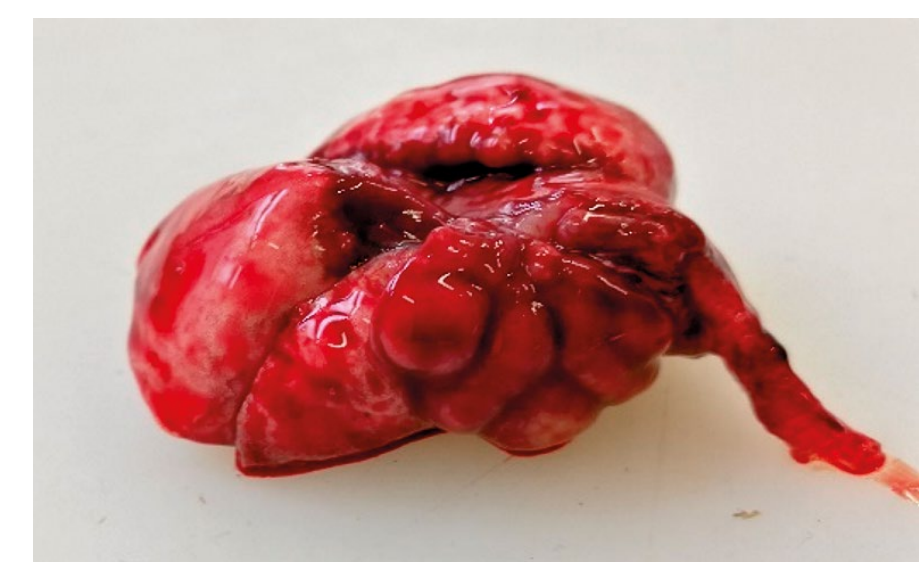

Fig. 3. Multiple bronchiectasis in a rat lung. Gross view

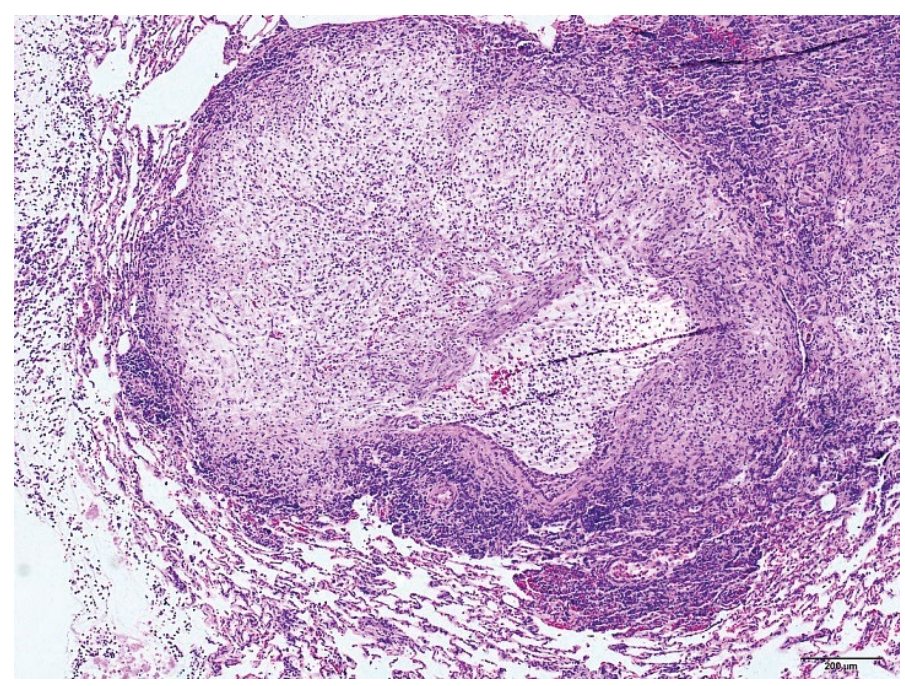

Fig. 4. Formation of large bronchiectasis in a rat lung. Lumen of dilatated bronchioli with the disrupted wall filled with proteinaceous material and inflammatory cells, granulation tissue arround. $\mathrm{HE}, \times \mathbf{4 0}$

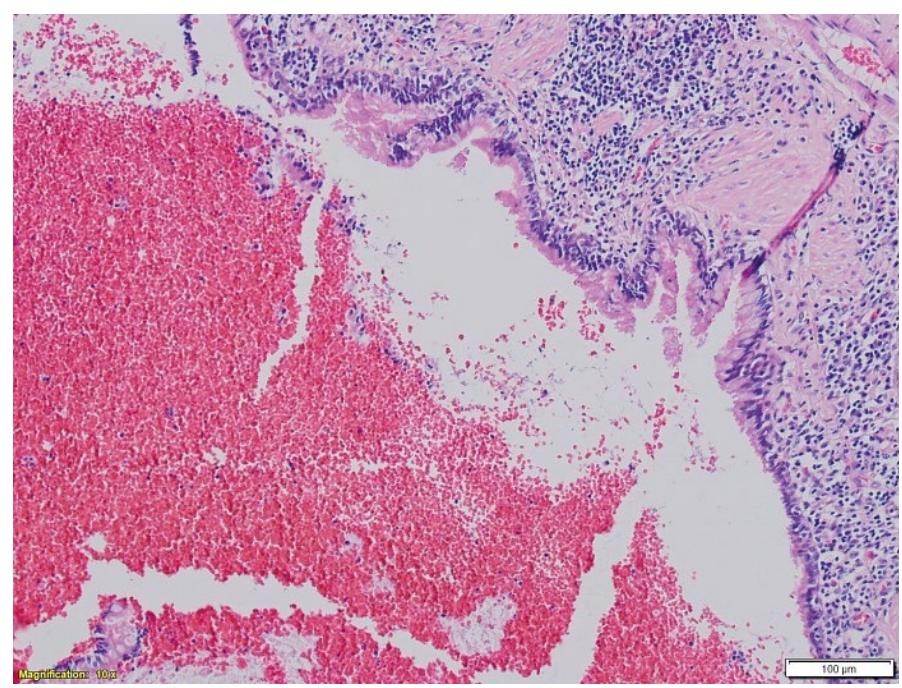

Fig. 5. Lumen of severe dilatated bronchus, filled with blood. HE, $\times 100$

enlarged, the wall was very thin, sometimes ruptured with severe proliferation of granulation tissue around, with flattened mucosa (in some animals the disapperance of mucosa epithelium was observed) (Fig. 4). The lumen was filled with mucinous or mucopurulent weak 
stained exudate rich in foamy alveolar macrophages, scattered neutrophils, some eosinophils (Fig. 4). In some animals we found bright yellow-orange stained interstitial macrophages and multiple areas of clusters of large, foamy interstitial macrophages around cholesterol clefts in the lung interstitial tissue near to bronchiectasis (Fig. 6). There was also a mild hemorrhage, blood was found in lumen of some bronchioli (Fig. 5). In cases of mice bronchiectasies bronchi and bronchioli were slightly dilatated, with unchanged epithelium, filled by purulent exudate with abundant accumulation of neutrophils (Fig. 9), in some animals with macrophages (Fig. 9), also a few eosinophils are found. The atelectasis was more expressed in rat lungs than in mice (44 animals and 29, respectively, $P=0.017$ ) (Fig. 2). During gross examination the lungs were fleshy and red in color, dark. Flat, empty, compressed alveoli were found under microscope.

The number of connective tissue mast cells in rats and mice lungs was evaluated in this study. The number

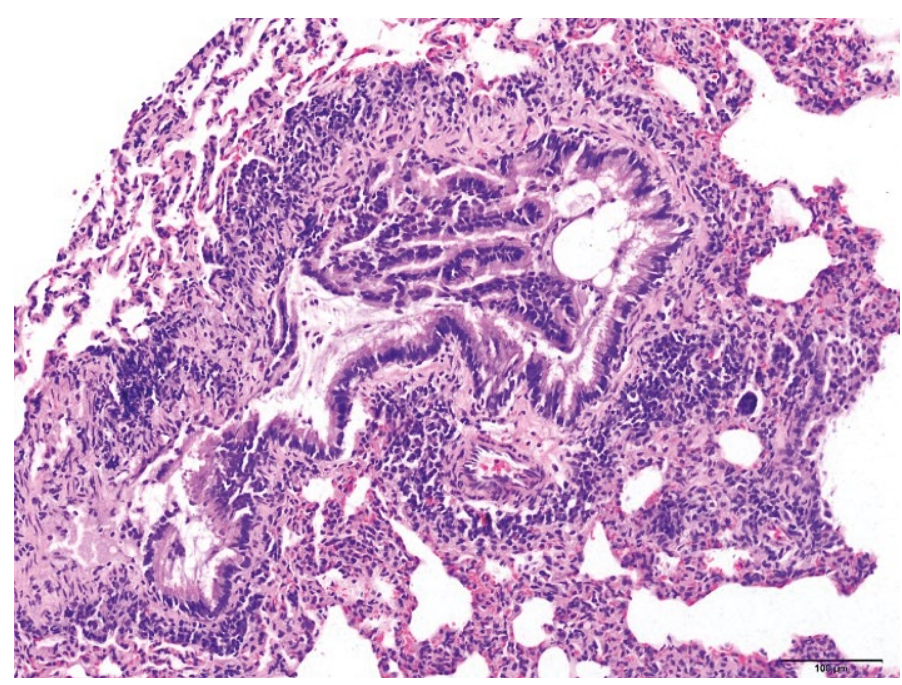

Fig. 7. Hyperplasia of bronchiolar mucosa in a rat lung. HE, $\times 100$

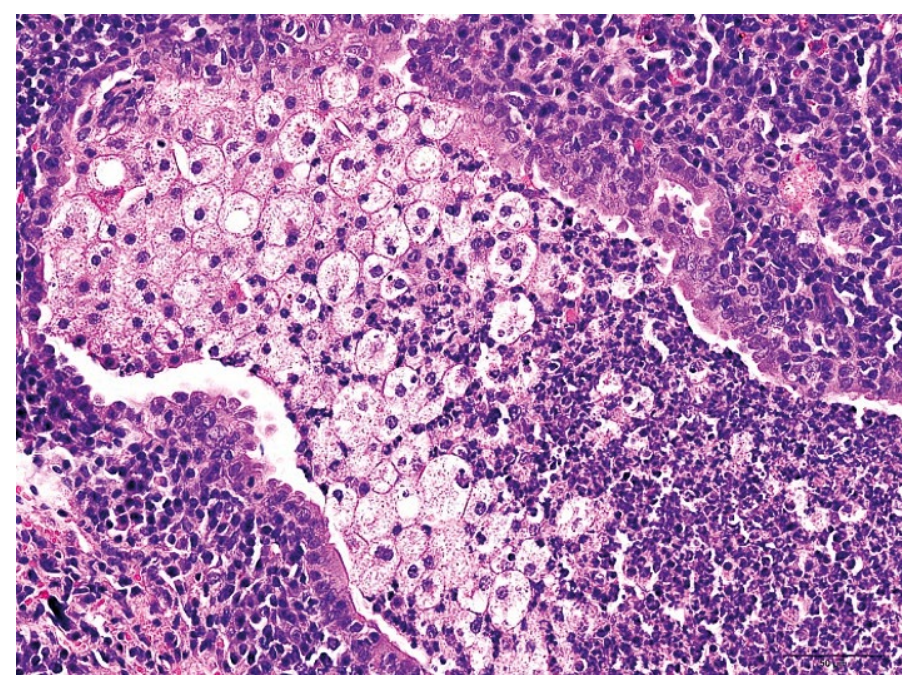

Fig. 9. Bronchiolitis (accumulation of neutrophils and marrcrophages) in a mouse lung. Lymphoid tissue hyperplasia arround bronchiole. $\mathrm{HE}, \times \mathbf{2 0 0}$

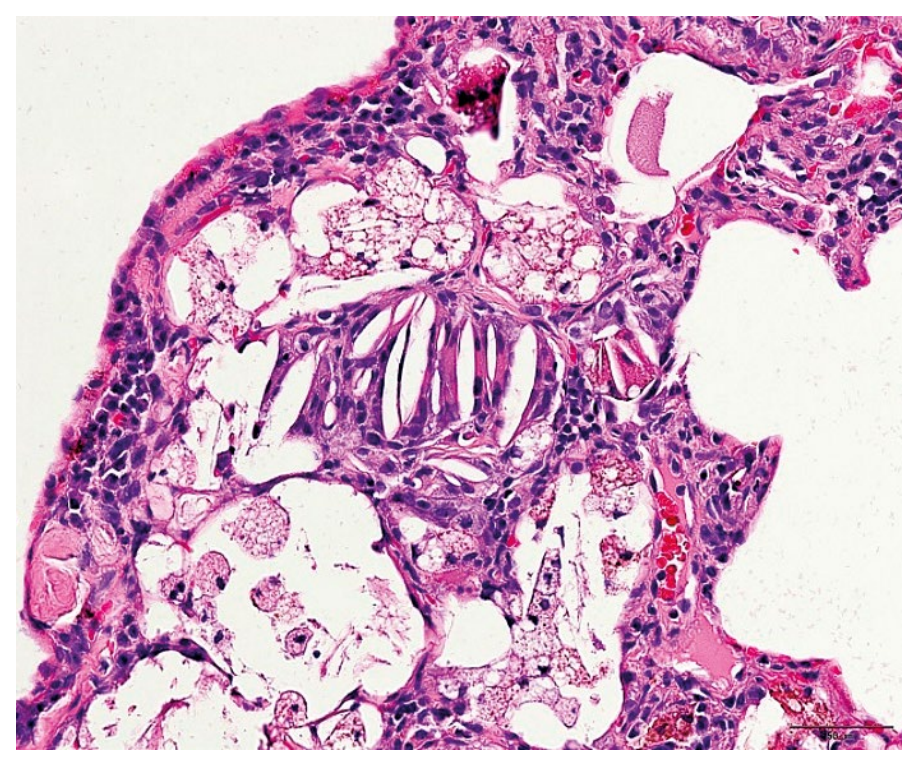

Fig. 6. Dilatated alveoli of a rat lung, accumulation of foamy macrophages, cholesterol crystals (white clefts) inside. Accumulation of lymfocytes in iterstitial tissue. HE, $\times 200$

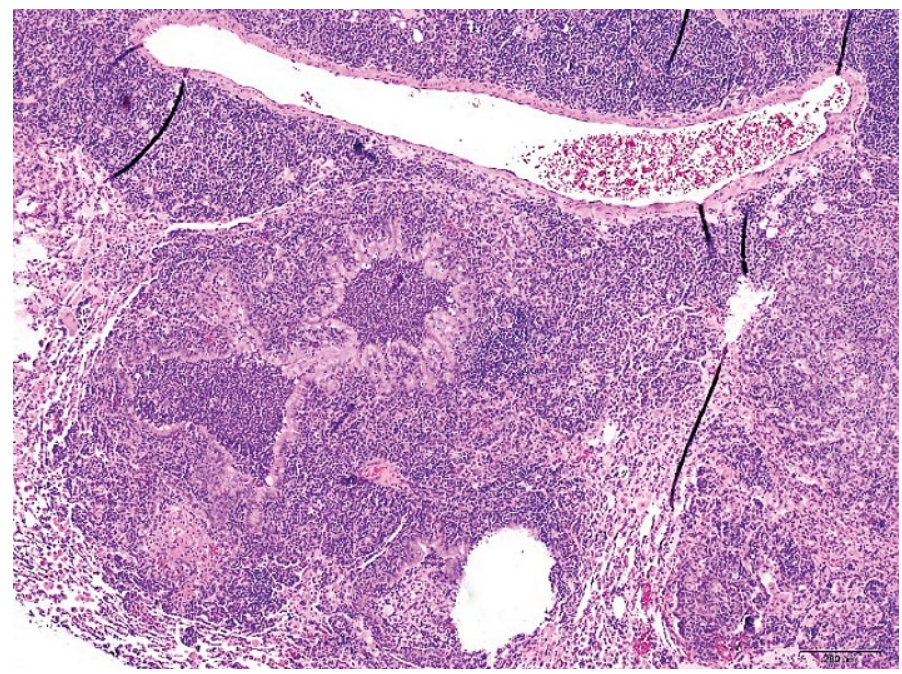

Fig. 8. Lymphoid tissue hyperplasia and bronchiolitis and bronchitis in a mouse lung. $\mathrm{HE}, \times 100$

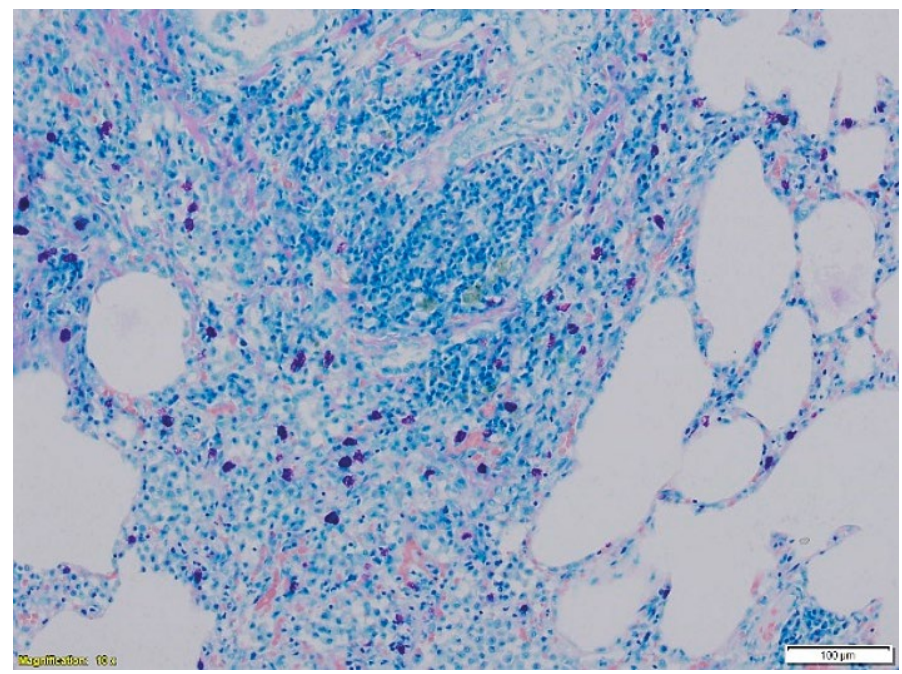

Fig. 10. Giemsa stained connective tissue mast cells in rat lung interstitial tissue. $\times 100$ 
of connective tissue mast cells was evaluated in both healthy and affected lungs of rats and mice in areas of bronchiectasis and lymphoid hyperplasia (Fig. 10). Significant differences were found between species $(\mathrm{P}<0.001)$ in healthy lungs. The number of mast cells was larger in the healthy lung tissue of rats (1.8 average at $\times 200$ magnification) than in mice (0.55 average at $\times 200$ magnification) (Tab. 1$)$. In lungs with inflammation, in areas of bronchiectasis, the number of mast cells was also larger in rats $(9.91$ average at $\times 200$ magnification) than in mice (2.36 average at $\times 200$ magnification), and, respectively, in areas of lymphoid hyperplasia - (1.67 average at $\times 200$ magnification) in mice (7.5 average at $\times 200$ magnification). The results of our study show a high amount of mast cells in both healthy and inflammed rats lung tissues compared to mice lungs. This indicates that the immune system response to the pathogen is more intense in rats than in mice. It is difficult to explain the distinct difference of mast cells number in rats and mice lungs. The presence of mast cells in tissues is also associated with autoimmune, allergic and immunological reactions because they release diverse chemicals capable of initiating and modulating such reactions $(14,19,26,39)$. Lung damage is related with mast cells granules and their biologically active substances, including heparin, histamine, and eosinophils chemotactic factor, leukotrienes, prostaglandins, serineproteases and cytokines $(4,8,34$, $35)$. Severe bronchiectasis in rats should be related to the presence of large amounts of mast cells (4.2 times more than in mice) because their secreted collagenase and other proteolytic enzymes cleaves collagen fibers, keeping in mind the fact that the network of collagen fibers in bronchial and bronchiolar wall connective tissue is abundant. In rat lungs in areas of bronchiectasis we found 9.99 mast cells in microscopic fields (MF) ( $\times 200$ magnification). Mast cells collagenase cause collagen necrosis $(3,25,28)$ of the skin in dog mast cells tumors. The study of bronchiectatic human lungs show a strong correlation between tryptase levels, degranulated MCs and activation of latent procollagenase and disease severity suggests that MCs may be involved in the inflammatory reaction in the BE lung $(14,34,39)$. Influenza infection induces a transient accumulation of lung MCs through the recruitment and maturation of $\mathrm{MCp}(44,45)$. According to references, influenza $\mathrm{C}$ virus in dogs and parainfluenza type 1 virus (Sendai) induced an increase in the number of bronchiolar MCs (45). The reason of a 4.2 times higher number of connective tissue cells in rat lungs compared to mice lungs remains unclear.

Another supposed factor related to severe rat bronchiectasis may be the presence of eosinophils. In our study we found infiltration with eosinophils in cases of pneumonia and bronchiolitis of rats and mice. These cells release large amont of mediators: TGF- $\beta$, basic fibroblast growth factors, platelet-derived growth factor, matrix metalloproteases, vascular endothelial growth factors, nerve growth factors, neuropeptides, cytokines such as IL-1 $\beta$ and IL-6 (7, 12, 20, 24, 30, $36,43)$. Eosinophils also release proteins, eicosanoids, leukotrienes, reactive oxygen species, and cell-cell signaling molecules $(7,10,12,20,41)$. These cells are related to pathological processes such as fibrosis, vascular leakage, angiogenesis, epithelial desquamation, epithelial metaplasia, smooth muscle hypertrophy (20) and with normal processes as bone metabolism, tissue repair/remodelation (367). Chronic inflammatory disorders, infectious diseases, neoplastic proccess are dependant upon participation of eosinophils (6).

Neutrophils were most commonly found in the cases of lung inflammation of rats and mice as well as bronchiectasis. Neutrophils contain in cytoplasmic granules myeloperoxidase, defensins, and proteinases (6), neutrophil elastase, cathepsin G, and proteinase 3 (12). According to the mast cells proteolytic enzymes, neutrophils elastases cleave elastic fibers of lung interstitial tissue and can also cause severe bronchiectasis $(17,34)$. Alveolar macrophages reside in the airspaces of the lung, whereas interstitial macrophages are found in the interstitial space between the alveoli and blood vessels and both types of macrophages are involved in chronic lung diseases. Besides the phagocytosis of external stimuli, macrophages are also responsible for the clearance of accumulating apoptotic cells to avoid the release of toxic intracellular substances which can cause secondary inflammation and inhibit tissue repair (22). Dysfunction of macrophages clearence in complicated severe pneumonia may also lead to bronchiectasis in rat lungs.

In our study, more severe interstitial pneumonia with bronchiectasis and lymphoid tissue hyperplasia in rats was associated with significantly higher number of mast cells in healthy and affected rat lung tissues. In our opinion, this is the result of a higher response of mast cells to the inflammatory process and impaired interaction between immune system cells.

\section{References}

1. Baker D. G.: Natural Pathogens of Laboratory Mice, Rats, and Rabbits and Their Effects on Research. Clin. Microbiol. Rev. 1998, 11, 231-266.

2. Beffus A. D., Pearce F. L., Gauldie J., Horsewood P., Bienenstock J.: Mucosal mast cells. Isolation and functional characteristics of rat intestinal mast cells. J. Immunol. 1982, 1982, 2475. 
3. Bostock D. E.: Neoplasms of the skin and subcutaneous tissues in dogs and cats. Br. Vet. J. 1986, 142, 1-19, doi: 10.1016/0007-1935(86)90002-3.

4. Bradding P., Walls A., Holgate S.: The role of the mast cell in he pathophysiology of asthma. J. Allergy Clin. Immunol. 2006, 117, 1277-1284.

5. Cesta M. F., Herbert R. A., Brix A., Malarkey D. E., Sills R. C.: Lung, epithelium, alveolus - hyperplasia, National Toxicology Program Nonneoplastic Lesion Atlas. U.S. Department of Health and Human Services, Public Health Service, National Toxicology Program. 2015, https://ntp.niehs.nih.gov/nnl/ respiratory/lung/epivhyp

6. Döring G.: The role of neutrophil elastase in chronic inflammation. Am. J. Respir. Crit. Care Med. 1994, 150, 114-117.

7. Enokihara H., Hamaguchi H., Sakamaki H., Hazama S., Saito K., Furusawa S., Shishido H.: Specific production of eosinophil colony stimulating factor from sensitized $\mathrm{T}$ cells from a patient with allergic eosinophilia. Br. J. Haematol. 1985, 59, 85-91.

8. Erjefält J.: Mast cells in human airways: the culprit? Eur. Respir. Rev. 2014, 23, 299-307.

9. Fagundes D. J., Taha M. O.: Choices criteria and current animal specimens. Acta Cir. Bras. 2004, 19, 59-65.

10. Frigas E., Loegering D. A., Gleich G. J.: Cytoxic effects of the guinea pig eosinophil major basic protein on tracheal epithelium. Lab. Invest. 1980, 42 $35-43$.

11. Graham J. E., Schoeb T. R.: Mycoplasma pulmonis in Rats. J. Exot. Pet. Med. 2011, 20, 270-276.

12. Gramegna A., Amati F., Terranova L., Sotgiu G., Tarsia P., Miglietta D., Calderazzo M. A., Aliberti S., Blasi F.: Neutrophil elastase in bronchiectasis. Respiratory Res. 2017, 18, 211-220, doi: 10.1186/s12931-017-0691-x.

13. Haines V. L.: The Ancient Rat. Vet. Clin. North Am. Exot. Anim. Pract. 2010 13, 95-105.

14. Hallgren J., Gurish M. F.: Pathways of murine mast cell development and trafficking: tracking the roots and routes of the mast cell. Immunol. Rev. 2007, 17, 8-18.

15. Hardy R. D., Coalson J. J., Peters J., Chaparro A., Techasaensiri C. H., Giavedoni L. D., Cantwell A. M., Kannan T. R., Baseman J. B., Dube P. H.: Analysis of Pulmonary Inflammation and Function in the Mouse and Baboon after Exposure to Mycoplasma pneumoniae CARDS Toxin. PloS One. 2009 4, 7562, doi: 10.1371/annotation/616385db-f413-4f23-ba78-2fe626870e46.

16. Hosseini E., Pedram B., Bahrami A. M., Moghaddam M. H. J., Javanbakht J. Ghomi F. E., Moghaddam N. J., Koohestani M., Shafiee R.: Cutaneous mast cell tumor (Mastocytoma): Cyto-histopathological and haematological investigations. Diagn. Pathol. 2014, 9, 9-12.

17. Hottendorf G. H., Nielsen S. W. Collagen necrosis in canine mastocytomas. Am. J. Pathol. 1966, 49, 501-513.

18. Irani A. M., Schwartz L. B.: Human mast cell heterogeneity. Allergy Proc. 1994, 15, 303-308

19. Ivanova I.: Mast cells in lung of rat. Trakia J. Sci. 2017, 3, 266-268.

20. Jacobsen E. A., Helmers R. A., Lee J. J., Lee N. A.: The expanding role(s) of eosinophils in health and disease. Blood. 2012, 120, 3882-3890, doi: 10.1182/ blood-2012-06-330845.

21. Jamur M., Grodzki A., Moreno A., de Mello L., de F. Pastor M. V., Berenstein E. H., Siraganian R. P., Oliver C.: Identification and isolation of rat bone marrow-derived mast cells using the mast cell-specific monoclonal antibody AA4. J. Hist. Cytochem. 2001, 49, 219-228.

22. Kapellos T. S., Bassler K., Aschenbrenner A. C., Fujii W., Schultze J. L. Dysregulated Functions of Lung Macrophage Populations in COPD. J. Immunol. Res. 2018, ID 2349045, 19 pages, doi: 10.1155/2018/2349045.

23. Komi A. D. E., Vöhler S., Bielory L.: Mast cell biology at molecular level: a comprehensive review. Clin. Rev. Allergy\&Immunol. 2019, doi: 10.1007/ s12016-019-08769-2.

24. McNeil H. P., Adachi R., Stevens R. L.: Mast cell-restricted tryptases: structure and function in inflammation and pathogen defense. J. Biol. Chem. 2007, 29, 20785-20789, doi: 10.1074/jbc.R700017200.

25. Misdorp $W$.: Mast cells and canine mast cell tumours. Veterinary Quarterly. 2004, 26, 156-169.

26. Nagasaka A., Matsue H., Matsushima H., Aoki R., Nakamura Y., Kambe N., Kon S., Uede T., Shimada S.: Osteopontin is produced by mast cells and affects IgE-mediated degranulation and migration of mast cells. Eur. J. Immunol. 2008, 38, 489-499.

27. Noli C., Miolo A.: The mast cell in wound healing. Vet. Dermatol. 2001, 12 303-313, doi: 10.1046/j.0959-4493.2001.00272.x.

28. PatnaikA. K., Ehler W. J., Macewen E. G.: Canine Cutaneous Mast Cell Tumor: Morphologic Grading and Survival Time in 83 Dogs Vet. Pathol. 1984, 21, 469-474

29. Percys D. H., Barthold S. W.: Pathology of Laboratory Rodents and Rabbits, $3^{\text {rd }}$ ed. 2007 , p. $33-35$.
30.Phipps S., Ying S., Wangoo A., Ong Y.-E., Levi-Schaffer F., Kay B. A.: The relationship between allergen-induced tissue eosinophilia and markers of repair and remodeling in human atopic skin. J. Immunol. 2002, 169, 4604-4612.

31. Razin E., Steven R. L., Akivama F., Schmid K., Austen K. F.: Culture from mouse bone marrow of a subclass of mast cells possessing a distinct chondroitin sulfate proteoglycan with glycosaminoglycans rich in N-acetylgalactosamine-4, 6-disulfate. J. Biol. Chem. 1982, 257, 7229.

32. Sengupta P.: Environmental and occupational exposure of metals and their role in male reproductive functions. Drug Chem. Toxicol. 2012, 36, 353-368.

33. Sengupta P.: The Laboratory Rat: Relating Its Age with Human's. Int. J. Prevent. Med. 2013, 6, 624-630.

34. Sepper R., Konttinen Y. T., Kemppinen P., Sorsa T., Eklund K. K.: Mast cells in bronchiectasis.: Ann. Med. 1998, 30, 307-315.

35. Silva da E. Z., Jamur M. C., Oliver C.: Mast cell function: a new vision of an old cell. J. Histochem. Cytochem. 2014, 62, 698-738.

36. Steven R. L., Lee T. D. G., Seldin D. C., Asuten K. F., Befus A. D., BienenstockJ. Intestinal mucosal mast cells from rats infected with Nippostrongylus brasiliensis contain protease-resistant chondroitin sulfate di-B proteoglycans. J. Immunol. 1986, 137, 291-300.

37. Timothy J., Williams J.: The eosinophil enigma. Clin. Invest. 2004, 113 507-509, doi: 10.1172/JCI21073.

38. Trivedi N. H., McNeal G., Rodriguez A. R., Yu J.-J., Forsthuber T. G., Arulanandam B. P.: Mast cells: multitalented facilitators of protection against bacterial pathogens. Expert Rev. Clin. Immunol. 2013, 9, 129-138, doi: 10.1586/eci.12.95.

39. Virk H., Arthur G., Bradding P.: Mast cells and their activation in lung disease. Transl. Res. 2016, 174, 60-76, doi: 10.1016/j.trsl.2016.01.005

40. Wasserman S. I. ̌z: The human lung mast cell. Environ. Health Perspect. 1984 55, 259-269.

41. Weidner N., Austen K. F.: Evidence for morphologic diversity of human mast cells. An ultrastructural and immunohistochemical study of mast cells from multiple body sites. Lab. Invest. 1990, 63, 63-72.

42. Weisbroth S. H., Kohn D. F., Boot R.: Bacterial, mycoplasmal and mycotic infections, [in:] Suckow M. A., Weisbroth S. H., Franklin C. L. (eds): The Laboratory Rat (ed 2). New York, NY, Academic Press 2006, p. 389-393.

43. Weller P., Spencer L.: Functions of tissue-resident eosinophils. Nature reviews. Immunol. 2017, 17, (12), doi: 10.1038/nri.2017.95.

44. Yotsumoto K., Okoshi Y., Shibuya K., Yamazaki S., Tahara-Hanaoka S. Honda S., Osawa M., Kuroiwa A., Matsuda Y., Tenen D. G., Iwama A., Nakauchi H., Shibuya A.: Paired activating and inhibitory immunoglobulinlike receptors, MAIR-I and MAIR-II, regulate mast cell and macrophage activation. J. Exp. Med. 2003, 198, 223-233.

45.Zarnegar B., Mendez-Enriquez E., Westin A., Söderberg C., Dahlin J. S., Grönvik K.-O., Hallgren J.: Influenza Infection in Mice Induces Accumulation of Lung Mast Cells through the Recruitment and Maturation of Mast Cell Progenitors. Front. Immunol. 2017, 22, doi: 10.3389/fimmu.2017.00310.

Corresponding author: Assoc. prof. Dr. Nomeda Juodziukyniene, Lithuanian University of Health Sciences, Mickeviciaus str. 9, Veterinary Academy, LT-44307, Kaunas, Lithuania; e-mail: Nomeda.Juodziukyniene@Ismuni.It 